\title{
Antinuclear Factor in Rapid and Slow Acetylator Patients Treated with Isoniazid
}

\author{
DAVID A. PRICE EVANS, M. F. BULLEN, J. HOUSTON, C. A. HOPKINS, \\ and J. M. VETTERS
}

\begin{abstract}
From the Department of Medicine, University of Liverpool, Aintree Hospital, Liverpool, and the Department of Pathology, University of Glasgow
\end{abstract}

It has been observed that tuberculous patients who had been treated with isoniazid exhibited positive antinuclear factor (ANF) tests more commonly than controls (Cannat and Seligmann, 1966). ANF can be considered a forerunner of the drug-induced systemic lupus erythematosus syndrome (AlarcónSegovia, 1969).

Both isoniazid and hydrallazine have been demonstrated to be polymorphically acetylated in man (Evans, 1968).

Perry, Sakamoto, and Tan (1967) and Perry et al (1970) have shown that the development of antinuclear factor in patients who have received treatment for hypertension with hydrallazine is more frequent in slow than in rapid acetylators.

In view of the above observations one of us (D.A.P.E.) suggested a survey of tuberculosis patients under treatment for serum ANF, acetylator phenotype, and other possible relevant factors.

\section{Materials and Methods}

Patients. Volunteer patients were investigated either as inpatients at Aintree Hospital, Liverpool or shortly after discharge when they were continuing their treatment as outpatients under clinic supervision. (There were three exceptions, all ANF negative, in which there were intervals of 2,3 , and 5 months between cessation of isoniazid therapy and the drawing of the blood specimen for ANF determination.) All available volunteer patients available during the period of the study were investigated (ie, there was no selection).

Sulfamethazine Phenotyping Procedure was as described in series I of Evans (1969). Fasting patients swallowed $160 \mathrm{mg}$ sulfamethazine (syn. sulphadimidine) per kg metabolically-active mass (ie, weight to the power of 0.7 ) as crushed tablets with a little water. Two hours after drug ingestion the patients were allowed tea (or coffee) and toast. Thereafter normal meals were

Received 10 May 1971. allowed. All urine excreted during 8 hours following drug ingestion was collected, and a portion stored at $-20^{\circ} \mathrm{C}$ to await analysis. A sample of venous blood was taken at 8 hours following drug ingestion; the serum separated and stored at $-20^{\circ} \mathrm{C}$ to await analysis.

For three patients the dosage and timing of the collection of the specimens were modified as detailed in series II of Evans (1969).

Estimation of Sulfamethazine Concentration in Urine and Serum. When the samples were thawed care was taken to ensure that the sulfamethazine and acetyl sulfamethazine were completely dissolved before analysis was performed. For this purpose urine samples were placed after thawing in a boiling water bath for 5 minutes, and thawed sera were placed in a $37^{\circ} \mathrm{C}$ incubator for 1 hour.

Free $(F)$ and total $(T)$ sulfamethazine concentrations were estimated in unknowns in duplicate and a range of standards at $2,4,6,8$, and $10 \mu \mathrm{g}$ sulfamethazine per $\mathrm{ml}$, together with suitable blanks, were processed in duplicate simultaneously.

The percentage of sulfamethazine acetylated is given by the formula:

$$
\frac{\mathrm{T}-\mathrm{F}}{\mathrm{T}} \%
$$

(see Evans and White [1964] for further details of the analytical technique).

Blood Samples for ANF Testing. Sera were stored at $-20^{\circ} \mathrm{C}$ and transferred frozen to the Department of Pathology, Western Infirmary, Glasgow. Information concerning acetylator phenotype was not available to the researcher (J.M.V.) who carried out the ANF tests.

ANF Tests. These tests were carried out as described previously (Wren et al, 1967). In each batch of tests known positive and negative sera were included to act as controls.

Statistical Techniques were standard (Bailey, 1959). 


\section{Results}

Acetylator Phenotyping. The results of all patients, except 4, are shown in the Figure.

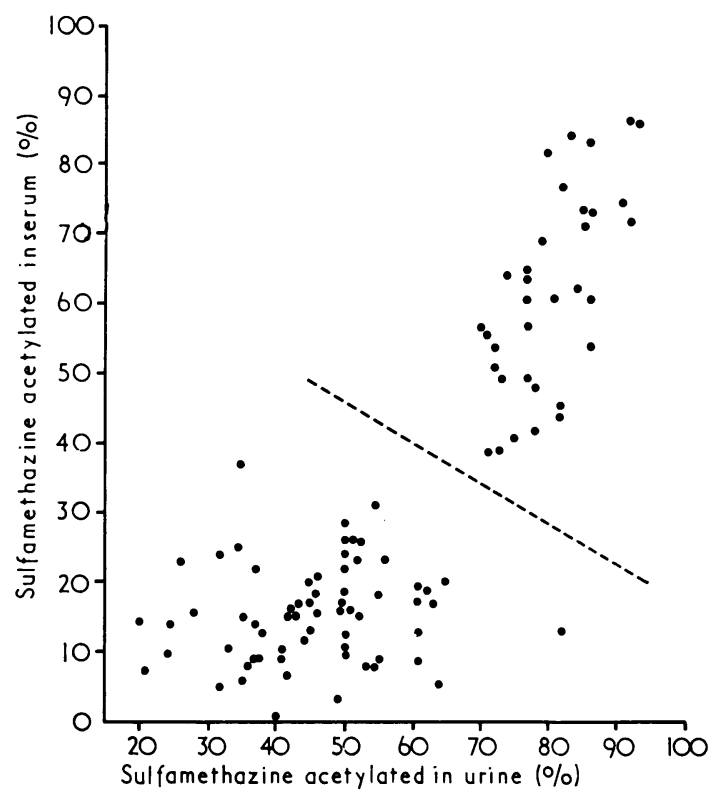

FIG. Acetylator phenotyping data on 99 patients. The dotted line separates slow and rapid acetylators. As explained in the text, the results of 4 patients are not shown on this scattergram.

The details concerning the 4 exceptions are as follows.

For one patient only the serum sample was available. The percentage of sulfamethazine in his serum was $17.05 \%$ and so this patient had been categorized a slow acetylator. Three patients were phenotyped by a modified technique (as series II of Evans, 1969) and they gave results indicating that two were slow acetylators and one a rapid acetylator.

Antinuclear Factor was found in the sera of 17 patients (16 male), whereas the sera of 86 patients (76 male) gave a negative test. As indicated in Table I there is no significant association between sex and ANF in the patients in this survey. ANF is usually found to occur more frequently in women than in men. The present series of patients, however, contained only a minority of women, and this fact may well account for the failure to demonstrate the usual sex incidence of ANF.

Six patients (all ANF negative) had been observed to be unreliable in taking their medications. One subject (ANF negative) had isoniazid-resistant tubercle bacilli and had been receiving isoniazid and
TABLE I

\begin{tabular}{|c|c|c|c|}
\hline \multicolumn{4}{|c|}{$\begin{array}{l}\text { SEX AND THE PRESENCE OF } \\
\text { ANTINUCLEAR FACTOR IN } \\
\text { TUBERCULOSIS PATIENTS }\end{array}$} \\
\hline $\begin{array}{c}\text { Antinuclear } \\
\text { Factor }\end{array}$ & Male & Female & Total \\
\hline $\begin{array}{l}\text { Positive } \\
\text { Negative }\end{array}$ & $\begin{array}{l}16 \\
76\end{array}$ & $\begin{array}{r}1 \\
10\end{array}$ & $\begin{array}{l}17 \\
86\end{array}$ \\
\hline Total & 92 & 11 & 103 \\
\hline
\end{tabular}

Fisher-Irwin exact probability 0.42 .

other drugs for 4 years, the quantities not being precisely known. He had received isoniazid during the hospitalization within the period of this study for 6 weeks, ceasing $5 \frac{1}{2}$ months before the blood for ANF determination was drawn. One subject (ANF positive) had received isoniazid for only one day before blood for ANF determination was drawn. These 8 subjects are excluded from the following results.

Full clinical details of satisfactory quality were available on 67 patients.

The disposition of ANF-positive results by acetylator phenotype is shown in Table II. There is no significant association.

TABLE II

\begin{tabular}{|c|c|c|c|}
\hline \multicolumn{4}{|c|}{$\begin{array}{l}\text { ACETYLATOR PHENOTYPE } \\
\text { AND THE PRESENCE OF } \\
\text { ANTINUCLEAR FACTOR IN } \\
\text { TUBERCULOSIS PATIENTS }\end{array}$} \\
\hline \multirow[t]{2}{*}{$\begin{array}{l}\text { Antinuclear } \\
\text { Factor }\end{array}$} & \multicolumn{2}{|c|}{$\begin{array}{l}\text { Acetylator } \\
\text { Phenotype }\end{array}$} & \multirow[t]{2}{*}{ Total } \\
\hline & Rapid & Slow & \\
\hline $\begin{array}{l}\text { Positive } \\
\text { Negative }\end{array}$ & $\begin{array}{r}4 \\
28\end{array}$ & $\begin{array}{l}12 \\
51\end{array}$ & $\begin{array}{l}16 \\
79\end{array}$ \\
\hline Total & 32 & 63 & 95 \\
\hline
\end{tabular}

In both rapid and slow acetylator phenotypes the ANF-positive patients were older than the ANFnegative patients (Table III). The mean age of 16 ANF-positive patients was $59 \cdot 81$ years (SE 2.27); and for 79 ANF-negative patients the mean age was 42.85 years (SE 1.74). The tests for the significance of the difference between the means gives $t=4.23$ and $\mathrm{p}<0.001$.

The length of exposure to isoniazid therapy (total range 22 to 112 weeks) and total dosage of isoniazid (total range 44 to $236 \mathrm{~g}$ ) consumed were not significantly different in ANF-positive as compared to ANF-negative patients when sub-divided by acetylator phenotype (Table III).

The drug most commonly used long-term with 
TABLE III

DATA ON PATIENTS WITH TUBERCULOSIS

\begin{tabular}{|c|c|c|c|c|c|c|c|}
\hline \multirow{2}{*}{$\begin{array}{l}\text { Acetylator } \\
\text { Phenotype }\end{array}$} & \multirow{2}{*}{$\begin{array}{l}\text { Anti- } \\
\text { nuclear } \\
\text { Factor }\end{array}$} & \multicolumn{2}{|r|}{ Age (yr) } & \multicolumn{2}{|c|}{ Weeks on Isoniazid } & \multicolumn{2}{|c|}{$\begin{array}{l}\text { Weight Isoniazid } \\
\text { Consumed (g) }\end{array}$} \\
\hline & & No. & Mean $\pm S D$ & No. & Mean $\pm S D$ & No. & Mean $\pm S D$ \\
\hline Rapid & Positive & 4 & $59.25 \pm 11.67$ & 4 & $62.44 \pm 28.53$ & 4 & $131 \cdot 10 \pm 59.93$ \\
\hline Rapid & Negative & 28 & $45 \cdot 61 \pm 16 \cdot 32$ & 20 & $51 \cdot 40 \pm 17 \cdot 46$ & 20 & $105 \cdot 57 \pm 38 \cdot 73$ \\
\hline Slow & Positive & 12 & $60.00 \pm 8.64$ & 12 & $45 \cdot 08 \pm 19 \cdot 12$ & 12 & $94.56 \pm 40.01$ \\
\hline Slow & Negative & 51 & $41.33 \pm 14.92$ & 31 & $51 \cdot 84 \pm 24 \cdot 31$ & 31 & $108 \cdot 76 \pm 51 \cdot 17$ \\
\hline \multicolumn{2}{|l|}{$F$} & \multicolumn{2}{|r|}{6.45} & \multicolumn{2}{|r|}{0.68} & \multicolumn{2}{|r|}{0.67} \\
\hline \multicolumn{2}{|l|}{ df } & \multicolumn{2}{|r|}{3,91} & \multicolumn{2}{|r|}{3,63} & \multicolumn{2}{|r|}{3,63} \\
\hline \multicolumn{2}{|l|}{$\mathbf{p}$} & \multicolumn{2}{|r|}{$<0.001$} & \multicolumn{2}{|r|}{$>0.20$} & \multicolumn{2}{|r|}{$>0.20$} \\
\hline
\end{tabular}

isoniazid was para-aminosalicylic acid (PAS). In the group of ANF-positive patients three were on drugs other than PAS together with isoniazidnamely ethambutol, cycloserine, and pyrazinamide. In the group of ANF-negative patients 14 had other drugs regularly in addition to isoniazid and PAS, and the drugs concerned are listed in Table IV. Almost all patients were also treated with a short initial course of streptomycin.

\section{TABLE IV}

\section{DRUGS OTHER THAN PAS TAKEN WITH ISONIAZID} BY ANF-NEGATIVE PATIENTS

\begin{tabular}{l|c}
\hline \multicolumn{1}{c|}{ Short Courses of Streptomycin } & (Most Patients) \\
\hline Prothionamide & $(1)$ \\
Pyrazinamide, prothionamide, and Librium & $(1)$ \\
Ethionamide & $(1)$ \\
Cycloserine & $(4)$ \\
Thiacetazone and cycloserine & $(1)$ \\
Tolbutamide & $(1)$ \\
Pyridoxine and Intal & $(1)$ \\
Thiacetazone & $(1)$ \\
Pyridoxine and Ferrogradumet & $(1)$ \\
Thiacetazone, pyrazinamide, and cycloserine & $(1)$ \\
Librium & $(1)$ \\
\hline
\end{tabular}

Disorders other than tuberculosis were of frequent occurrence in the patients surveyed, both ANF positive and ANF negative. None of the associated disorders noted in the ANF-positive patients were conditions known of themselves to be associated with a raised incidence of ANF (see Table V).

\section{Discussion}

The incidence of ANF in the tuberculosis patients in this survey was approximately $17 \%$ and this is considerably higher than the incidence commonly found in random population surveys. For example, in the paper of Wren et al (1967) amongst 66
TABLE V

\begin{tabular}{l|c}
\multicolumn{1}{c}{$\begin{array}{c}\text { DISORDERS OTHER THAN TUBERCULOSIS } \\
\text { RECORDED AS PREVIOUS ILINESSES } \\
\text { IN 16 ANF-POSITIVE PATIENTS }\end{array}$} & \begin{tabular}{c} 
Times \\
Condition* \\
\multicolumn{1}{c}{ Cocorded } \\
(n)
\end{tabular} \\
\hline & 1 \\
\hline Pleurisy & 1 \\
Peptic ulcer & 3 \\
Duodenal ulcer with operation & 1 \\
Myocardial infarction & 1 \\
Lichen simplex & 2 \\
Multiple sclerosis & 1 \\
Pneumonia & 1 \\
Epistaxis & 2 \\
Bronchiectasis & 1 \\
Gonorrhoea, cystitis, and urethritis & 1 \\
Asthma & 1 \\
Fibrositis & 1 \\
\hline
\end{tabular}

* Excluding childhood infections.

fathers of mongol children only one had ANFpositive serum, and amongst 67 fathers of control (normal) children none had an ANF-positive serum. This population of men lived in the same area, were tested by the same laboratory technique, and had a similar mean age to the patients with tuberculosis surveyed. (The tuberculosis patients had a mean age of 45 and a range of 12 to 76 years.) The incidence of ANF positivity in the patients treated for tuberculosis by Cannat and Seligmann (1966) was $20 \%$, and Alarcón-Segovia (1969) states: "We have recently confirmed such higher incidence of antinuclear antibodies in isoniazidtreated tuberculosis patients.' Cannat and Seligmann (1968) were able to demonstrate the experimental induction of ANF by isoniazid in mice.

It would appear from the present survey that sex, acetylator phenotype, concomitant disease, and concomitant drug therapy (with isoniazid and PAS) are not related to the presence of ANF in patients treated for tuberculosis. Therefore it seems 
reasonable to suspect that isoniazid is responsible especially since hydrallazine (which, like isoniazid, is hydrazine with a substituent group on one nitrogen atom) causes ANF development in hypertensives.

There is a polymorphism in man for the metabolism of some drugs acetylated by hepatic $\mathrm{N}$-acetyl transferase (Evans and White, 1964). Perry et al (1967) and Perry et al (1970) have shown that slow acetylators are more susceptible to the development of ANF, when treated for hypertension with hydrallazine, than are rapid acetylators. The present survey indicates that the same does not hold true for the use of isoniazid in conventional doses for the treatment of tuberculosis.

Age emerges as a significant factor in the present survey in that ANF-positive patients are significantly older than ANF-negative patients. Cannat and Seligmann (1966) also found an increased incidence of ANF positivity in elderly (over 60 ) patients treated for tuberculosis. The presence of ANF is not a disease but can be considered a fore-runner of disease which may develop in some patients. (Alarcón-Segovia, 1969). It is possible, therefore, that the age-relationship of ANF development may be relevant to the known greater statistical predisposition of the elderly to adverse reactions to drugs (Hurwitz, 1969).

\section{Summary}

One hundred and three patients undergoing treatment for tuberculosis have been studied for acetylator phenotype and the presence of antinuclear factor in the serum. Seventeen patients were found to have antinuclear factor. The presence of antinuclear factor was not associated with either acetylator phenotype, sex, dosage of isoniazid, other disease concomitant with tuberculosis, or other therapy concomitant with isoniazid and paraaminosalicylic acid. Patients with antinuclear factor were significantly older than those without.

We wish to thank the United Liverpool Hospitals Medical Research Committee (Chairman, Professor C. A. Clarke, FRS) and the Nuffield Foundation (via Professor C. A. Clarke, FRS) for generous financial support. Thanks are also due to Mr Luke C. Eze, FIMLT, for sulfamethazine estimations. Mrs Hazel Groon, Western Infirmary, Glasgow, for assistance in performing the ANF tests. Sister Ellis and Mr Davies, Ward Staff, and also the Medical Records Staff of Aintree Hospital, Liverpool. The medical and clerical staff at the following clinics in the Liverpool area: North Chest Clinic, South Chest Clinic, East Chest Clinic, Bootle Chest Clinic, and Waterloo Chest Clinic.

\section{REFERENCES}

Alarcón-Segovia, D. (1969). Drug-induced lupus syndromes. Mayo Clinic Proceedings, 44, 664-681.

Bailey, N. T. J. (1959). Statistical Methods in Biology. English Universities Press, London.

Cannat, A. and Seligmann, M. (1966). Possible induction of antinuclear antibodies by isoniazid. Lancet, 1, 185-187.

Cannat, A. and Seligmann, M. (1968). Induction by isoniazid and hydrallazine of antinuclear factors in mice. Clinical and Experimental Immunology, 3, 99-105.

Evans, D. A. P. (1968). Genetic variations in the acetylation of isoniazid and other drugs. Annals of the New York Academy of Sciences, 151, 723-733.

Evans, D. A. P. (1969). An improved and simplified method of detecting the acetylator phenotype. Fournal of Medical Genetics, 6, 405-407.

Evans, D. A. P. and White, T. A. (1964). Human acetylation polymorphism. Fournal of Laboratory and Clinical Medicine, 63, 394403.

Hurwitz, N. (1969). Predisposing factors in adverse reactions to drugs. British Medical fournal, 1, 536-539.

Perry, H. M. Jr., Sakamoto, A., and Tan, E. M. (1967). Relationship of acetylating enzyme to hydralazine toxicity. (Abstr.) Fournal of Laboratory and Clinical Medicine, 70, 1020-1021.

Perry, H. M., Jr., Tan, E. M., Carmody, S., and Sakamoto, A. (1970). Relationship of acetyl transferase activity to antinuclear antibodies and toxic symptoms in hypertensive patients treated with hydralazine. Fournal of Laboratory and Clinical Medicine, 76 114-125.

Wren, P. J. J., Evans, D. A. P., Vetters, J. M., and Chew, A. (1967). Autoimmune antibodies in mongol families. Lancet, 2, 186-188. 